function in chronic airflow obstruction. Am Rev Respir Dis 1986;134:276-80

3 Burrows B, Bloom JW, Traver GA, Cline MG. The course and prognosis of different forms of chronic airways obstruction in a sample from the general population. $N \mathrm{Engl} F \mathrm{Med}$ 1987;317:1309-14.

4 Taylor RG, Joyce H, Gross E, Holland F, Pride NB. Bronchial reactivity to inhaled histamine and annual rate of decline in FEV1 in male smokers and ex-smokers. Thorax 1985;40:9-16.

5 Peat JK, Woolcock AJ, Cullen K. Rate of decline of lung function in subjects with asthma. Eur $\mathcal{F}$ Respir Dis 1987;70:171-9.

SIR,-It has recently become fashionable to question the value of continuous treatment with $\beta$ agonists in asthma. Constant $P$ van Schayck and colleagues' study is one of few studies supporting a nihilistic attitude towards this principle of treatment and extends it to other bronchodilators. ' The authors conclude that bronchodilators should be used only on demand, with additional corticosteroid treatment if necessary. The study, however, shows a very small decline in forced expiratory volume in one second $\left(\mathrm{FEV}_{1}\right)$ in the continuously treated groups (salbutamol and ipratropium bromide). This decline borders on significance $(p=0.05)$ when confounding factors are considered, and it is stated that the decline was 0.029 (SE 0.036) $1 /$ year less during the year in which salbutamol was used than during the year in which ipratropium bromide was used; this must mean that no significant decline occurred during salbutamol treatment (the combined analysis showed a decline of $0.072 \mathrm{l} /$ year during continuous treatment and $0.020 \mathrm{l} /$ year during treatment on demand. Did the statistical power of the study really permit the inference that the two drugs had equal effects in this respect?

We also believe that there are methodological problems with the study: firstly, a fairly heterogeneous group of patients was studied, with about two thirds having chronic bronchitis; secondly, the drop out rate was high as only 144 out of 223 patients were included in the key analysis; and, thirdly, baseline $\mathrm{FEV}_{1}$ in the groups receiving continuous and on demand treatment differed more than did the yearly changes observed (approximately 0.2 litres in favour of the group receiving on demand treatment). The only possible difference with regard to histamine sensitivity was a transiently reduced sensitivity in patients with asthma treated on demand. This does not seem logical.

The authors' main conclusion, that continuous treatment should not be used, is thus not supported by convincing data. A study by Sears et al, which is quoted in support, cannot be properly evaluated owing to a lack of primary data in the published paper. ${ }^{2}$ Current opinion in Sweden and other countries favours the use of continuous treatment with $\beta$ agonists only in combination with inhaled steroids. Thus van Schayck and colleagues' main conclusion is based on weak data from a study not designed according to presently accepted treatment strategies. Their warning against using long acting $\beta$ stimulants (see their discussion) seems even more far fetched: they were not even studied.

KJELL LARSSON PAUL HJEMDAHL

National Institute of Occupational Health,

S-171 8+ Solna

Sweden

I Van Schayck CP, Dompeling E, van Heerwarden CLA, Folgerin $H$, Verbeek ALM, van der Hoogen HJM, et al. Bronchodilator treatment in moderate asthma and chronic bronchitis: continuous or on demand? A randomised controlled study. B.M 1991;303:1426-31. (7 December.)

2 Sears MR, Taylor DR, Print CG, Lake DC, Li Q, Flammery EM, et al. Regular inhaled $\beta$-agonist treatment in bronchial asthma. Lancet 1990;336:1391-6.

AUTHORS' REPLY, - In their letter ${ }^{1}$ about our article $^{2} \mathrm{C} \mathrm{J}$ Hilton and $\mathrm{R}$ W Fuller report an improved $\mathrm{FEV}_{1}$ in 55 patients who received $200 \mu \mathrm{g}$ salbutamol regularly for 12 months. They claim that continuous use of salbutamol does not decrease lung function. We wonder what daily dose of salbutamol these 55 patients actually received. Our 83 patients who were treated on demand used an average daily dose of $240 \mu \mathrm{g}$ salbutamol for two years. The decline in $\mathrm{FEV}_{1}$ was only $0.020 \mathrm{l} /$ year. The 61 patients who were treated continuously in our study received $1600 \mu \mathrm{g}$ salbutamol daily for two years and had a decline in $\mathrm{FEV}_{1}$ of $0.072 \mathrm{1} /$ year $(\mathrm{p}=0.05)$. We assume that the 55 patients reported on by Hilton and Fuller received considerably less than $200 \mu \mathrm{g}$ salbutamol eight times a day. To support the claim that regular use of salbutamol alone does not worsen the disease a randomised comparison should be made with treatment on demand, preferably over a period long enough for effects on the decline in lung function and not the immediate effects of giving the drugs to be studied.

Hilton and Fuller suggest that the difference between their and our findings may be related to the effect of stopping anti-inflammatory drugs. Previous treatment was not, however, a confounder in our randomised trial. The patients who stopped using anti-inflammatory drugs were equally distributed over the two treatment regimens. Hilton and Fuller further suggest that our results can be explained by more severe asthma in our continuously treated patients, but the decline was corrected for potential confounding variables such as initial $\mathrm{FEV}_{1}$ and symptoms. After this correction the decline in continuous treatment remained three to four times greater than that in treatment on demand. The estimated influence $(\beta)$ of stopping anti-inflammatory drugs on the decline in lung function in patients treated continuously $(-0.015 \mathrm{l} /$ year) was comparable with that in patients treated on demand $(-0.0161 /$ year $)$.

In Hilton and Fuller's study the number of patients who dropped out seems comparable with the number in our study who used an average dosage of $240 \mu \mathrm{g}$ salbutamol daily and dropped out after 12 months: eight out of $63(13 \%)$ in their study versus 14 out of $110(13 \%)$ in our study.

Andy Lawton and Maria Teresa Lopez-Vidriero are probably unaware of our other article, which shows the influence of, for example, bronchial hyperresponsiveness on decline in lung function. ${ }^{3}$ This study was carried out in the same study population as that used in our study reported in the $B M F .{ }^{2}$ The two groups of patients -51 asthmatic patients and 93 patients with chronic bronchitiswere analysed separately, and thus each group was homogeneous. There were similar intervals of six months between measurements, and $\mathrm{FEV}_{1}$ was always measured at exactly the same time of the day to avoid diurnal variation. Bronchodilator drugs were stopped for at least eight hours before the start of the measurements.

Our article shows that the measurements of $\mathrm{FEV}_{1}$ clearly fit a linear model. This model explained a variation of more than $70 \%$. We did not use autoregression analysis except afterwards to reanalyse our data. In doing this we took only equally spaced time points.

We are surprised that Kjell Larsson and Paul Hjemdahl consider the decline in $\mathrm{FEV}_{1}$ in the continuously treated group to be very small. The crossover design for the two drugs and the parallel design for the two treatment regimens does not allow a simple comparison as suggested. Both drugs were given to all 144 patients for one year and compared within patients. There was no significant difference in the decline in lung function between the two drugs $(p=0 \cdot 41)$.

Only 23 patients dropped out from the study for reasons unrelated to the drug treatment, such as lack of motivation. This is low for a two year study. Forty patients dropped out because the treatment with bronchodilators was not sufficient. In this group twice as many patients were treated continuously. This is an important finding.

Our findings seem to support the current opinion in Sweden that continuous $\beta_{2}$ agonists should be used only in combination with inhaled steroids. We showed that patients receiving continuous bronchodilator treatment were unaware of an increased decline in lung function. Therefore we suggested that continuous bronchodilation without anti-inflammatory treatment masks the decline in lung function and suppresses the subjective need for additional anti-inflammatory treatment. As long acting $\beta_{2}$ agonists seem even more effective in suppressing symptoms such as morning dyspnoea we suggest that patients may be more misled by the apparent wellbeing produced by these long acting bronchodilators.

C P VAN SCHAYCK

E DOMPELING

C VAN WEEL

R P AKKERMANS

Nijmegen University,

PO Box 9101,

Nijmegen $6500 \mathrm{HB}$

Netherland

1 Hilton CJ, Fuller RW. Bronchodilator treatment in asthma: continuous or on demand? BMF 1992;304:121. (11 January.)

2 Van Schayck CP, Dompeling E, van Herwaarden CLA, Folgering $\mathrm{H}$, Verbeek ALM, van der Hoogen $\mathrm{HJM}$, et al. Bronchodilator treatment in moderate asthma and chronic bronchitis: continuous or on demand? A randomised controlled bronchitis: continuous or on demand? A randomise
study. $B M \mathcal{J}$ 1991;303:1426-31. (7 December.)

3 Van Schayck CP, Dompeling E, van Herwaarden CLA, Wever AMJ, van Weel C. Interacting effects of atopy and bronchial $A M J$, van Weel C. Interacting effects of atopy and bronchial
hyperresponsiveness on the annual rate of decline in lung hyperresponsiveness on the annual rate of decline in lung
function and the exacerbation rate in asthma. Am Rev Respir Dis 1991;144:1297-301.

\section{Coronary heart disease}

SIR, - J McMurray and H J Dargie put forward a compelling case for including heart failure in the initiative The Health of the Nation.' They point out that the Framingham study shows that the annual incidences of heart failure in subjects aged 65 and over and subjects aged under 65 are only slightly lower than those of myocardial infarction and higher than those of stroke. The Framingham study was begun in 1949 and refers to an American population in which the causes (particularly hypertension) and the treatment of heart failure were different from those today. There is a dearth of epidemiological information on heart failure not only in the United Kingdom but throughout the world, largely because epidemiologists have concentrated on coronary heart disease manifest by sudden death, myocardial infarction, or angina. We recently studied the prevalence of heart failure in three general practices ${ }^{2}$ and the impact of heart failure on workload in a district general hospital.

The prevalence of heart failure in a population of 30204 people in north west London was $0.4 \%$. The prevalence was $0.06 \%$ in those aged under 65 and $2 \cdot 8 \%$ in those aged 65 and over (mean 73 ). Heart failure was determined by an analysis of prescriptions for diuretics and a clinical definition. Hypertension at any time was identified in only $6 \%$ of those with heart failure.

In Hillingdon Hospital, which serves roughly 155000 patients, 2877 patients were admitted to the medical and geriatric services over six months. ${ }^{3}$ Of these, 140 had heart failure as the main reason for admission, of whom 15 had heart failure as a complication of myocardial infarction. Twenty nine patients were aged under 65. Sixty two patients died within one year of admission. By comparison, during the same six months 89 patients were admitted to the coronary care unit with acute myocardial infarction and 52 with unstable angina. Of the patients with myocardial infarction, 55 were aged under 65 . A few patients with these conditions might have been admitted directly to the wards, particularly the geriatric wards.

In his response to McMurray and Dargie, Hugh Tunstall-Pedoe is reticent about the importance of heart failure for four reasons. ${ }^{+}$Firstly, the main problem is in patients over the age of 65 ; that is 